\title{
Sequential nature of damage annealing and activation in implanted GaAs
}

\author{
J. L. Tandon, J. H. Madok, and I. S. Leybovich \\ McDonnell Douglas Astronautics Company, Huntington Beach. California 92647
}

G. Bai and M-A. Nicolet

California Institute of Technology, Pasadena, Califomies 91125

(Received 10 October 1988; accepted for publication 18 November 1988)

\begin{abstract}
Rapid thermal processing of implanted GaAs reveals a definitive sequence in the damage annealing and the electrical activation of ions. Removal of implantation-induced damage and restoration of GaAs crystallinity occurs first. Irrespective of implanted species, at this stage the GaAs is $n$-type and highly resistive with almost ideal values of electron mobility. Electrical activation is achieved next when, in a narrow anneal temperature window, the material becomes $n$-or $p$-type, or remains semi-insulating, commensurate to the chemical nature of the implanted ion. Such a two-step sequence in the electrical doping of GaAs by ion implantation may be unique of GaAs and other compound semiconductors.
\end{abstract}

Progress in the understanding of ion implantation in GaAs has been hampered by several issues.' Above all, the creation, mature, and annealing of implantation-induced camage has not been well characterized. ${ }^{1-j}$ High processing temperatures, invariably required for annealing implantation damage and activation of ions, result in the partial dissociation of $\mathrm{GaAs}^{4}$ and/or changes in the original electronic properties of the material. ${ }^{3,5,6} \mathrm{~A}$ detailed quantitative study of such high-temperature effects is lacking. Unquestionably, all these issues infuence the final depth profles of electrical activity in the implanted and annealed layers. ${ }^{7,8}$

Fundamentals of annealing in implanted GaAs are addressed in this letter. The short times involved with rapid thermal annealing (RTA) provide new insight into the mechanism of damage annealing and dopant activation in GaAs.

Implantation studies were carried out in undoped $\langle 100\rangle$ semi-insulating GaAs. ${ }^{28} \mathrm{Si}^{+},{ }^{24} \mathrm{Mg}^{+}$, or ${ }^{40} \mathrm{Ar}^{+}$ions were implanted at room temperature with energies of 70,55 , or 90 $\mathrm{keV}$, respectively, to yield approximately similar projected ranges for the ions in GaAs. In all cases the dose was fixed at $5 \times 10^{13} \mathrm{~cm}^{-2}$. After implantation, the samples were coated with an $\sim 1000$-A-thick silicon nitride film on the implanted side. The samples were then annealed at different temperatures in a $\mathrm{RTA}$ system with forming gas ambient. All annealings were carried out with a temperature rise rate of $\sim 120^{\circ} \mathrm{C} / \mathrm{s}$, and in the cycle the samples were held at the reported final temperature for $5 \mathrm{~s}$ before cool down.

Following annealing, sheet carrier concentrations and carrier mobilities in the samples were determined by Halleffect measurements. Lattice strain in the samples was monitored by Bragg-case $x$-ray double-crystal diffactometry (DCD, "rocking curves"), with the Fe $K \alpha_{1}$ (400) symmetric refection. For the present implantations the lattice strain is proportional to the damage induced. "On selected samples, standard photoluminescence (PL) measurements were carried out at $\sim 5 \mathrm{~K}$, using an $\mathrm{Ar}{ }^{+}$ion laser $(\lambda=514.5 \mathrm{~nm})$ as an excitation source.

Resuits of electrical measurements made on the impianted and annealed samples are summarized in Fig. 1.
Sheet carrier concentrations $\left(N_{s}\right.$ or $P_{s}$ ) and carrier mobilities $\left(\mu_{n}\right.$ or $\left.\mu_{p}\right)$ are plotted against annealing temperature (T). Irrespective of the implanted ion, in all cases, the asimplanted and the low-temperature annealed samples exhibit $n$-type conduction, as determined by Hall effect. This electrical conduction is characterized by extremely low values of mobility, and may be attributed to tunnel-assisted hopping between disordered states. ${ }^{10}$ A dramatic behavior during annealing of the implants is observed in the temperature range
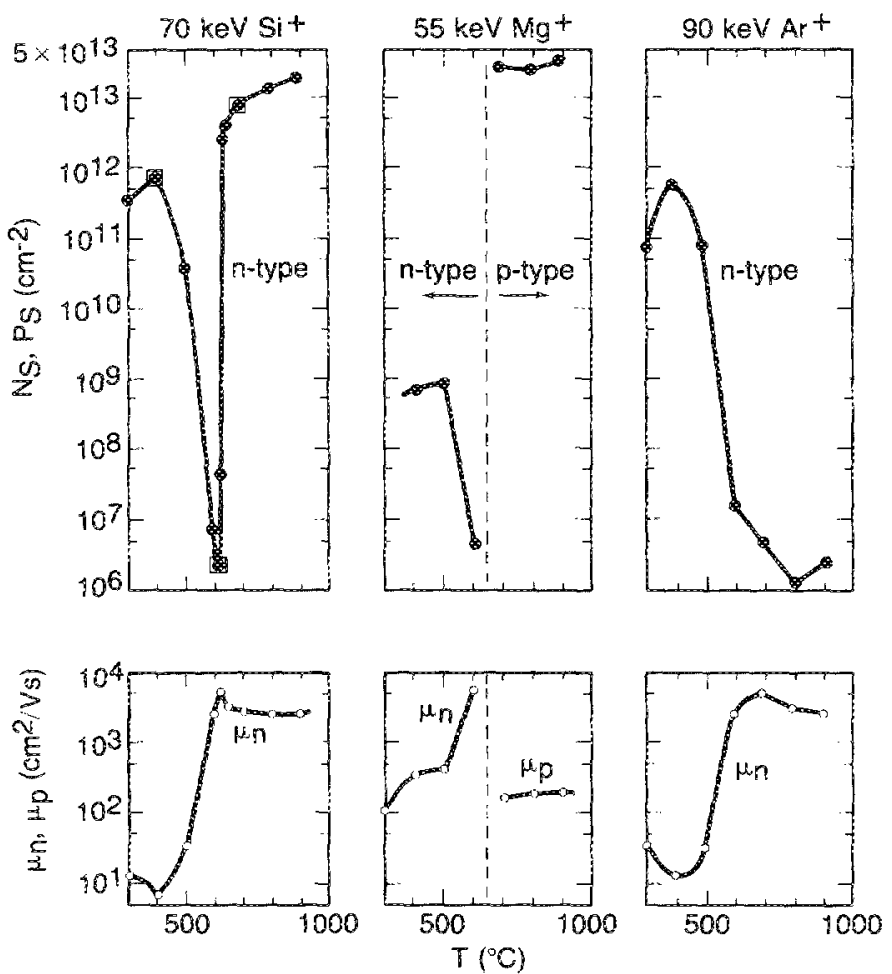

FIG. 1 . Sheet carrier concentration $\left(N_{s}, P_{b}\right)$ and carrier mobility $\left(\mu_{n}, \mu_{p}\right)$ measurements made on (GaAs samples implanted with $70 \mathrm{keV} \mathrm{Si}^{+}, 55 \mathrm{keV}$ $\mathrm{Mg}^{+}$, and $90 \mathrm{keV} \mathrm{Ar}^{+}$, as a function of annealing temperature ( 7 ) for a fixcd nominal duration of $5 \mathrm{~s}$. The ion dose in all cases is fixed at $5 \times 10^{13}$ cm '2 "Boxed" data points on the $N_{s}$ curve for the Si implants represent samples on which $x$-ray rocking curve and photoluminescence measurements were taken (Figs. 2 and 3 ). 
$400-625^{\circ} \mathrm{C}$. The $N_{s}$ value drops several orders of magnitude, while the electron mobility in the samples rises correspondingly. At $\sim 625^{\circ} \mathrm{C}$, a minimum value in $N_{s}$ is reached. At this stage the material becomes highly resistive (semi-insulating), but is still $n$-type, regardless of the implanted ion. The electron mobility in the samples also attains its highest value, approaching to that of a good quality GaAs $(-7000$ $\left.\mathrm{cm}^{2} / \mathrm{Vs}\right)$. Beyond $625^{\circ} \mathrm{C}$, in a narrow temperature range $\left(\sim 625-675^{\circ} \mathrm{C}\right)$, a sharp increase in the electrical conductivity of the Si- and the Mg-implanted samples occurs, whereas the Ar-implanted samples continue to remain highly resistive. The chemical nature of the implanted ions only becomes evident at this point. As expected, the Si- and the Mgimplanted samples exhibit $n$-and $p$-type conduction, respectively. The Ar-implanted samples, on the other hand, remain semi-insulating in their properties, like the original starting material. A further increase in the annealing temperature up to $900^{\circ} \mathrm{C}$ results in an increase in the $N_{s}$ values of the Siimplanted samples, and virtually no change in the $P_{s}$ or the $N_{s}$ values of the $\mathrm{Mg}$ - and the Ar-implanted samples, respectively. A slight decrease in the electron mobility of the Siimplanted samples now may be attributed to the effects of scattering due to activated and ionized Si impurity. At $900^{\circ} \mathrm{C}$ the electrical activation is $\sim 50 \%$ for Si and $\sim 80 \%$ for $\mathrm{Mg}$.

The annealing behavior of implanted GaAs, as characterized by the electrical measurements of Fig. 1 , is further supported by DCD and PL data. Measurements made on the Si-implanted samples annealed at the critical points of the "dip" in the $N_{s}$ curve of Fig. 1 (at 400,625 , and $700^{\circ} \mathrm{C}$ ) are presented in Figs. 2 and 3, respectively.

Latice-strain measurements made by DCD are extremely sensitive in detecting ion-implantation-induced damage. ${ }^{9,11}$ The asymmetric rocking curve for the $400^{\circ} \mathrm{C}$ annealed sample (Fig. 2) clearly shows that, at this temperature, implantation-induced damage is not completely removed. Annealing at $625^{\circ} \mathrm{C}$ or beyond restores good crystailinity of GaAs, as evidenced by the symmetric curve of the 625 and $700^{\circ} \mathrm{C}$ annealed samples.

PL measurements are sensitive to radiative (electronic) changes in the materiai. Referring to Fig. 3, PL spectra show that the 400 and $625^{\circ} \mathrm{C}$ annealed samples possess almost identical radiative transitions, which are similar to the origi-

$\mathrm{PO} \mathrm{keV} \mathrm{Si+}$
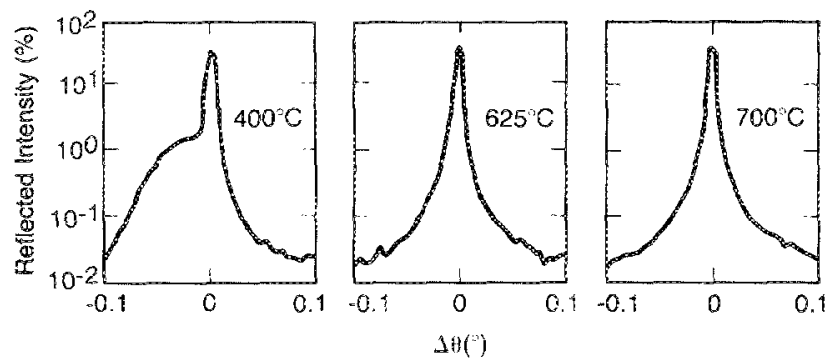

FIG. 2. (400) $\mathrm{Fe} \mathrm{K \alpha}$, x-ray rocking curve measurements periormed with symmetric refiection on three of the Si-implanted and annealed samples from Fig. 1 ("boxed" points). The intensiey of the refected $x$-ray beam is plotted against the rocking angle $(\Delta \theta)$, which is measured with respect to the Bragg-case refection angle at $\Delta \theta \cdots 0$.

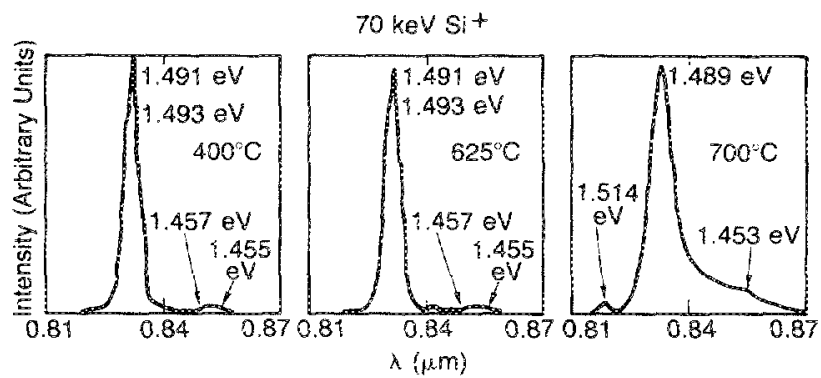

FiG. 3. Photoluminescence (PL) spectra obtained at $-5 \mathrm{~K}$ on the Si-implanted and annealed samples of Figs. 1 and 2 .

nal semi-insulating GaAs material. ${ }^{6}$ As suggested in the literature $^{12,13}$ the peaks at 1.491 and $1.493 \mathrm{eV}$ may be related to a carbon impurity in semi-insulating material, with 1.491 eV representing a neutral donor-neutral carbon acceptor $\left(D^{0}-C^{0}\right)$ transition, and $1.493 \mathrm{eV}$ a free electron-neutral carbon acceptor $\left(e-C^{6}\right)$ transition. The low-intensity peaks at 1.455 and $1.457 \mathrm{eV}$ are $L O$ phonon replicas of the peaks at 1.491 and $1.493 \mathrm{eV}$, respectively. Upon annealing at $700^{\circ} \mathrm{C}$, a significant change in the $\mathrm{BL}$ spectrum is observed. The new dominant peak at $1.489 \mathrm{eV}$ can now be ascribed to an overlapping of the previous carbon-associated peaks with a free eiectron-neutral Si acceptor transition $\left(e-\mathrm{Si}^{\circ}\right)$ at $1.485 \mathrm{eV} .{ }^{13}$ A barely detected shoulder at $1.453 \mathrm{eV}$ is a $L O$ phonon replica of this transition. Also, a low intensity peak appears at $1.514 \mathrm{eV}$, which is due to an exciten bound to a neutral donor $\left(D^{0}, X\right){ }^{14}$ The $\mathrm{PL}$ data thus indicate that the radiative (electronic) properties of the Si-implanted samples are only transformed after annealing at $700^{\circ} \mathrm{C}$. This is because of the electrical activation of the implanted Si in GaAs.

Electrical, $\mathrm{DCD}$, and $\mathrm{PL}$ measurements performed on implanted and annealed GaAs, as described above, complement each other in establishing a definitive sequence in the removal of implantation-induced damage and the electrical activation of the implanted dopants. Electrically, implantaton-induced damage in GaAs is n-type in character, irrespective of the chemical nature of the implanted ion. During annealing, this induced damage anneals out first, before the implanted ions can be electrically activated. Removal of implantation damage (at $\sim 625^{\circ} \mathrm{C}$ ) results in $n$-type GaAs with almost ideal values of electron mobility, once again, independent of the chemical nature of the implanted ion. Electrical activation of the implanted ions occurs next, in a narrow annealing temperature window of $625-675^{\circ} \mathrm{C}$, and is commensurate to the chemical nature of the ions. The electrical data of Fig. 1 substantiate these conclusions. Specifcally, for Si-implanted and annealed samples, DCD measurements confrm that implantation-induced damage is indeed completely removed at $625^{\circ} \mathrm{C}$ (Fig. 2). Corresponding PL measurements (Fig. 3 ) verify that the implanted ions in GaAs are not electrically active at this stage, but become so only at anneal temperatures beyond $625^{\circ} \mathrm{C}$.

It should be pointed out that the existence of a sequence in the annealing of implantation-induced damage and the electrical activation of ions in GaAs are perhaps only revealed when annealing is carried out with RTA. The short times involved with RTA somewhat provide "snap-shots" of 
the annealing process. The sequence is found to be dependent on the time and temperature of annealing, and is not generated by RTA itself. It aiso appears to exist during furnace annealing of inplanted GaAs. ${ }^{10}$ In this sense, RTA simply acts as a convenient probe for detecting it.

A question arises whether the annealing sequence reported here is typical of GaAs and other compound sermiconductors. Does it also occur in elemental semiconductors? To address this question, a corresponding experiment was conducted by implanting $P$ in Ge. Induced damage and electrical characteristics of $\mathrm{P}$ in Ge were expected to be very nearly similar to those of Si in GaAs (because of the comparable masses of the ions and the host lattices). RTA of the $P_{-}$ implanted Ge samples did not show the kind of dramatic behavior as observed for the Si-implanied GaAs samples, for the time scale considered. Thus, if a similar annealing sequence exists for implanted $\mathrm{Ge}_{\text {, it is }}$ weak, as it could not be detected by the results of the experiments. Studies of the present type in other compound semiconductors have not been carried out, but are clearly needed to confirm whether the sequence is unique of compound semiconductors.

At McDonnell Douglas, this work was supported by internal research and development funds, and at Caltech by the National Science Foundation, MRG grant DMR8421119. We are indebted to E. Haller and 5 . Beeman, Uni- versity of California Lawrence Berkeley Laboratory, for educating us on ion implantation effects in Ge. We also gratefully acknowledge their contribution in providing us $\mathrm{P}$ implanted ultrapure Ge samples. At McDonnell Douglas, we thank M. C. Stonage for her assistance with implantations.

'J. \$. Williams, Mater. Res. Soc. Symp. Proc. 35, 427 (1985).

${ }^{2}$ K. D. Cummings, S. J. Pearton, and G. P. Vella-Coleiro, J A Apl. Phys. 6st, 163 (1986).

${ }^{3}$ J. L. Tandon, J. H. Madok, I. S. Leybovich, and G. Bai, Mater. Res. Soc. Symp. Proc. 126, 207 (1988).

'Y. J. Chan and M. S. Lin, J. Appl. Phys. 60, 2184 (1986).

${ }^{5}$ M. Matsui and T. Kazano, Appl. Whys. Lett. 51, 659 (1987).

'I. L. Tandon, I. S. Leybovich, and G. Bai (unpublished).

${ }^{7}$ A. Musuyama, M-A. Nicolet, I. Golecki, J. L. Tandon, D. K. Sadana, and

I. Washburn, Appl. Phys. Lett. 36, 749 (1980).

${ }^{8}$ S. S. Gill, and B. J. Sealy, J. Electrochem. Soc. 133, 2590 (1986).

${ }^{9}$ B. M. Paine, N. N. Hurvitz, and V. S. Speriosu, J. Appi. Phys. 61, 1335 (1987).

"Y. Kato, T. Shimada, Y. Shiraki, and K. F. Komatsubara, J. Appl. "'hys. 45, 1044 (1974).

"18. M. Paine and Y. S. Speriosu, J. Appl. Phys. 62, 1704 (1987).

K. Akimoto, M. Dohsen, M. Arai, and N. Watanabe, Appl. Phys. Lett. 45, $922(1984)$.

${ }^{13}$ D. J. Ashen, B. J. Dean, D. T. J. Hurle, J. B. Mullin, A. M. White, and P. D. Greene, J. Phys. Chem. Solids 36, 1041 (1975).

${ }^{14} U$. Hein and P. Hiesinger, Phys. Status Soldi B 66, 461 (1974). 